\title{
The Home Office Mental Health Unit ${ }^{\dagger}$
}

\author{
Jayanth Srinivas, Sarah Denvir \& Martin Humphreys
}

\begin{abstract}
Over the years, the number of mentally disordered offenders in England and Wales subject to restriction orders has steadily increased. The Home Secretary, through the Mental Health Unit at the Home Office, is responsible for overseeing the treatment of these individuals. As psychiatrists work in partnership with the Mental Health Unit in the treatment of these patients, it is essential to understand the Unit's role and functions. In this article, we describe the philosophy, structure and functions of the Mental Health Unit and its statutory role in the care of mentally disordered offenders subject to restriction orders.
\end{abstract}

Involvement of the Home Office in the development of forensic psychiatric services can be traced back to the 19th century. In 1800, following the attempted murder of George III by James Hadfield, the Criminal Lunatics Act was passed to allow for the detention in safe custody of insane persons charged with offences of treason, murder or felony and acquitted on the grounds of insanity or found insane on arraignment. Such persons were admitted to a criminal asylum in London's Bethlem Hospital, which was soon overcrowded with mentally ill prisoners. The Criminal Lunatics Asylum Act 1860 made possible the building of the first separate special asylum, Broadmoor Hospital in Berkshire. The Home Office was given responsibility for running Broadmoor Hospital, as well as Rampton and Moss Side Hospitals in the north of England, which opened subsequently. The setting up of the National Health Service in 1948 saw the transfer of ownership of these three high-security hospitals to the Ministry of Health (now the Department of Health). However, the Home Office still continued to control the admission and discharge of patients at Broadmoor Hospital. Following the introduction of the Mental Health Act in 1959, the Department of Health became the manager of all three hospitals and controlled admissions to them. The Home Office

${ }^{+}$For a commentary on this article see pp. 459-461, this issue. retained control over the detention of restricted patients.

Today, the Home Secretary oversees the treatment of mentally disordered offenders subject to restriction orders, restriction directions or hospital directions under the Mental Health Act 1983 in England and Wales. Such offenders are known as 'restricted patients'. The number of restricted patients has increased steadily from 2337 in 1993 to about 4600 (Box 1) in England and Wales today. This increase might be linked to various causes, including a greater risk of violence by people with mental disorders (Brennan et al, 2000), growing

\section{Box 1 Characteristics of restricted patients in} England and Wales today

Of the 4600 restricted patients:

- about 760 are in high secure hospitals

- about 1270 are living in the community under supervision

- about 550 are female

- $69 \%$ have a sole diagnosis of mental illness

- $11 \%$ have a sole diagnosis of psychopathic disorder

- $50 \%$ have a conviction for violence (652 for homicide)

- $13 \%$ have a conviction for a sexual offence

Jayanth Srinivas is a consultant forensic psychiatrist at the Hatherton Centre (St George's Hospital, Corporation Street, Stafford ST3 1AG, UK. Email: Jayanth.Srinivas@ssh-tr.nhs.uk). He is also an associate clinical teacher at the Warwick Medical School. His main clinical and research interests include liaison with the Home Office and organisation and development of a range of forensic services. Sarah Denvir is a casework manager in the Home Office Mental Health Unit in London. She has casework responsibility for about 760 'restricted patients' as well as policy responsibility for leave for restricted patients, supervision in the community and women's services. Her liaison responsibilities include hospitals and prisons within the South-Eastern Forensic Commissioning Area, and the Institute of Psychiatry Forensic Teaching Unit. Martin Humphreys is a senior lecturer in forensic psychiatry at the University of Birmingham and an honorary consultant forensic psychiatrist with the Birmingham and Solihull Mental Health NHS Trust. His research interests include mental health law and forensic rehabilitation. 
emphasis on public protection (Department of Health, 1998, 1999), improved risk assessment and risk management techniques and expansion in secure psychiatric services that provide treatment for mentally disordered offenders (following the Glancy and Butler reports: respectively Department of Health and Social Services, 1974; Home Office \& Department of Health and Social Services, 1975).

In the case of restricted patients, the Home Secretary has certain powers to protect the public from them. On a day-to-day basis, these powers are managed by the Mental Health Unit at the Home Office. The Unit also develops and implements government policy on reducing the risk posed by mentally disordered offenders. It is part of the Health Partnerships Directorate and is responsible both to the National Offender Management Service (part of the Home Office) and to the Care Services Directorate of the Department of Health. The Home Secretary has no clinical role in the management of restricted patients, which is the responsibility of psychiatrists and the secure hospitals. The role of the Home Office in assessing the risk to the public therefore differs from that of the clinical team, but the two are interdependent in discharging their responsibilities.

\section{The legislation in England and Wales}

\section{Hospital orders and restriction orders}

Section 41 of the Mental Health Act 1983 enables a Crown Court, when it makes a hospital order under Section 37, also to impose a restriction order, which then places certain responsibilities on the Home Secretary. A court may impose a restriction order on an offender only when it appears necessary for the protection of public from serious harm. A restriction order may be made for a limited period or without limit of time.

\section{Transfer of prisoners to hospital}

Sections 47 and 48 of the Mental Health Act 1983 allow the Home Secretary, on receipt of two medical recommendations, to direct that a prisoner be sent to hospital for psychiatric treatment. Under Section 49 , the Home Secretary may impose restrictions until the time when the prison sentence would normally have ended.

\section{Structure of the Mental Health Unit}

The Mental Health Unit has 67 staff, divided into nine caseworking teams (Box 2), a management team and a team dealing with the short Bill to amend
Box 2 Structure of the caseworking side of the Mental Health Unit

- Head of the Mental Health Unit (jobshare)

- Head of casework

- 6 casework managers

- 9 senior caseworkers

- 23 caseworkers

- 12 administrative officers

- 5 administrative assistants

the Mental Health Act 1983 (Department of Health, 2004). The case-load is divided alphabetically by patients' surnames. Cases are never left unattended and caseworkers cover for each other when necessary. The Unit operates an out-of-hours service in the evenings and at weekends to deal with any situation that needs an urgent decision.

\section{Principles and approach of the Mental Health Unit}

The work of the Mental Health Unit contributes to the Home Office's mission to 'build a safe, just and tolerant society'. The purpose of the Unit is to protect the public from further offending by dangerous restricted patients, by supporting their effective care in hospital and by assisting in their safe rehabilitation into the community.

The Home Secretary has various powers (Box 3) designed to ensure that the public is adequately protected from these individuals. These powers are concerned with managing a restricted patient's contact with the community. The Mental Health Unit therefore carries out its work through thorough risk assessment and risk management.

\section{Box 3 Powers of the Home Secretary}

Without the permission of the Home Secretary, the RMO cannot:

- give a restricted patient leave from hospital

- transfer the patient to another hospital

- remit the patient to prison

- discharge the patient into the community

- recall the patient from the community

- remit to stand trial a patient who has been found unfit to plead, made subject to a restriction order and recovers sufficiently to stand trial 


\section{Risk assessment and risk management}

When the Mental Health Unit receives a request for the Home Secretary's consent for leave, transfer or discharge of a restricted patient, the request is assessed for evidence that any risk to the public has been properly identified and evaluated, and that sound measures have been taken to guard against risk. The questions asked include:

- how likely is it that the patient will do harm?

- in what circumstances might the risk of harm arise?

- how is it proposed to avoid those risky circumstances?

- has a procedure been identified for picking up the signs if something does go wrong, and for taking appropriate action?

The Unit judges a proposal by looking at the following factors:

- the quality and range of the information given

- the completeness and objectivity of the analysis provided

- concrete evidence that the patient has made progress

- realistic forward planning.

\section{Shared goal, different approaches - risk reduction}

Owing to a difference in their backgrounds (clinical $v$. non-clinical), 'responsible medical officers' (RMOs) and the Home Office can differ in their approach to risk reduction. Whereas the RMOs have to balance issues such as clinical care of the patient and the therapeutic relationship against risk reduction, the Home Office has to balance the need for public protection against the patient's rights. Such a difference in approach could give rise to differences in mutual perception.

The RMOs sometimes perceive the Mental Health Unit as being overcautious and slow to respond to their requests. Furthermore, as a body that lacks clinical expertise, it may ask further questions about the patients or require additional information, thereby delaying the process. The Unit is centrally located in London and therefore can be seen as not only geographically distant, but also remote from the reality of the situation. On the other hand, the Mental Health Unit can perceive doctors as being too close to their patients, sometimes relying on patients' recent progress and minimising past events or issues in order to achieve success (such as leave or discharge for their patients). Such differences in perception could affect the working relationship between the Unit and RMOs. Differences in approach to risk, however, are important and often result in morethorough risk assessments and in achieving the same goal of risk reduction.

\section{Functions of the Mental Health Unit}

The Mental Health Unit handles all the applications and requests and serves several functions involving restricted patients in England and Wales (Box 4).

\section{Community leave}

Section 17 of the Mental Health Act 1983 allows RMOs to grant a detained patient leave of absence from hospital. However, for restricted patients, the consent of the Home Secretary is needed before this leave can be agreed. The Home Secretary's consent is not needed for a patient to appear in court in connection with his or her case or to be escorted to another hospital for emergency treatment. Well thought out leave that serves a definable purpose and is carefully and sensitively carried out has an important part to play in the treatment and rehabilitation of restricted patients. It also provides valuable information to help RMOs, the clinical teams and the Home Office to manage the patient in hospital and to help all parties, including the Mental Health Review Tribunal, when considering discharge into the community.

The Mental Health Unit can grant leave, including escorted or unescorted daytime leave, overnight leave and trial leave, following an appropriate

\section{Box 4 Mental Health Unit's activities}

In 2004-5, the Unit took over 15000 decisions on behalf of the Home Secretary, which included:

- reviewing 6380 reports on restricted patients from community supervisors

- recalling 160 patients from the community to secure hospitals

- risk assessment on 2548 requests for community leave

- assessing 454 requests for transfers between hospitals

- authorising 872 transfers from prison to hospital

- preparing 4005 statements for Mental Health Review Tribunals 
application made in an approved form to allow a proper risk assessment to be carried out. Trial leave is given for patients being transferred between hospitals, particularly when a move from a high secure hospital to a hospital of lower security is involved. The advantage of trial leave is that the patient can be returned quickly to the originating hospital if problems occur.

The Mental Health Unit issues guidance to RMOs to help them provide the Home Office with all the information needed to assess leave proposals. The most recent guidance (Home Office, 2006) includes an application form for leave and a pro forma for reporting back on leave taken, together with a checklist of some of the risk factors to be considered when proposing leave.

In any request for leave for a restricted patient, the Mental Health Unit looks for the aims of the proposal, its planned benefits to the patient's treatment and/or rehabilitation, an assessment of any risk of harm to the public arising from the proposal, and the nature and adequacy of the safeguards implemented against any specific identified risk. It expects RMOs to consider all other risk factors that apply to the particular patient, including those relating to victims and their families. The request should also set out the contribution that the leave is expected to make to future assessments of the patient's likely behaviour and to plans for managing the patient's rehabilitation. It should relate to the framework of the overall care and treatment programme to which the clinical team is working, and should set personal objectives for the patient.

In the majority of cases, the Mental Health Unit gives consent for leave at the RMO's discretion. This means that the number of leaves granted will not be limited, but the Unit relies on RMOs' discretion to apply rigorous standards of risk assessment and management. It expects leave programmes to be designed and conducted in a way that will preserve public safety and sustain public confidence in the arrangements as a whole, and that will respect the feelings and possible fears of victims and others who may have been affected by the offences. The arrangements must also take into account the real clinical needs of the individual patient.

\section{Discharge from hospital}

In England and Wales, restricted patients can be discharged from hospital only with the agreement of the Home Secretary or an independent Mental Health Review Tribunal. Discharge is normally ordered subject to conditions, with absolute discharge granted only following a conclusion that the patient no longer needs specialist supervision for the protection of others. When the Mental Health Act
1983 came into effect, it gave Mental Health Review Tribunals powers to discharge restricted patients both conditionally and absolutely. According to Mental Health Unit statistics, the ratio of discharges of patients between tribunal panels and the Home Secretary was roughly 50:50. That ratio subsequently fell to 90:10, although in the vast majority of these cases there had been no discharge proposal put to the Home Office.

It appears that many psychiatrists have long perceived the Home Office as a conservative organisation with an extremely guarded and cautious approach towards the prospect of discharge. Anecdotally, the prevailing view has been that there is little point in putting a discharge proposal to the Home Office when the likelihood of a discharge by a Mental Health Review Tribunal might be much greater. However, this view seems to be gradually changing in face of encouragement by the Home Office to put discharge proposals to it when the clinical team can demonstrate that the patient is ready to return to the community. The Home Secretary has recently been making about $25 \%$ of all discharge decisions.

Discharge into the community is a difficult issue because of the commensurate risks involved, but increasing the proportion of discharges made by the Home Secretary is nevertheless a priority for the Mental Health Unit. It prevents patients being detained in hospital longer than necessary and frees beds. It may also save the patient from the stress of having to attend a tribunal hearing. Another advantage is that the patient will not have a lengthy wait on a deferred conditional discharge while the arrangements are made, as any discharge package put to the Mental Health Unit must have these in place already. Consequently, the 2-month decision time will be the most that the patient will have to wait. Importantly, it also allows the clinical teams and the Mental Health Unit to work together towards discharging the patient at a time when he or she is ready and when the necessary follow-up arrangements are in place.

\section{Information required by the Mental Health Unit when considering discharge}

Apart from the fact that the patient no longer meets the requirements to be detained under the Mental Health Act, the Mental Health Unit needs to be confident that:

- the care team has fully addressed all the risk factors associated with the patient's mental disorder and offending behaviour and that the patient has some insight into these factors

- the patient has adhered to medication regimens 
- the patient has appropriately used any leave in the community

- an appropriate care package is in place in the community, including arrangements for supervision

- appropriate accommodation has been identified.

This list is, of course, not exhaustive as different factors will affect each patient. The Home Office will provide the care team with a full explanation of reasons if an application is turned down.

\section{Conditionally discharged patients}

Once a restricted patient has been discharged, either by a Mental Health Review Tribunal or by the Home Secretary, RMOs have a statutory duty under Section 41(6) of the Mental Health Act 1983 to provide reports, their frequency directed by the Secretary of State, on the progress of the individual in the community.

The first report is required 1 month after the date of discharge, and then usually at 3-monthly intervals. The reports should be thorough and should address all aspects of the individual's progress. The clinical supervisor should also inform the Mental Health Unit immediately of any untoward incident, so that the Unit can consider whether it is appropriate to recall the individual to hospital. It is crucial for the safe management of restricted patients in the community that supervisors' reports are delivered regularly and in good time and that the Unit is assiduous in pursuing any that are not.

\section{Mental Health Review Tribunals}

Mental Health Review Tribunals have no statutory role in the rehabilitation or care of restricted patients, nor is a tribunal a judicial substitute for the Home Secretary's powers. The Home Office has the status of an interested party in respect of a restricted patient's tribunal. The Mental Health Unit must be sent copies of all written evidence put before a tribunal and in turn must provide its comments on this evidence. The Home Office's statement will contain a detailed description of the index offence and a list of previous convictions, together with the Home Office's observations on the reports provided by the detaining hospital. The Mental Health Unit has 3 weeks from receipt of the reports in which to provide this statement (2 weeks in the case of recalled patients) and meets these targets in $98 \%$ of cases (Box 5). Any further reports that are submitted, for example on behalf of the patient through their solicitor, will be responded to by supplementary statements from the Home Office.

\section{Box 5 Targets of the Mental Health Unit}

- $100 \%$ of Mental Health Review Tribunal statements within 3 weeks (statutory target)

- Leave decisions within 3 weeks

- Trial leave and discharge decisions within 2 months

At this stage, the statement from the Home Office will, necessarily, oppose discharge. As the Home Secretary can himself discharge restricted patients, it follows that, if the discharge request had originally been submitted to the Home Office he would have conditionally discharged the patient himself, had he thought it appropriate. Broadly, there are four different types of scenario covered by the Home Office statement to the tribunal:

- no one supports discharge

- some reports support discharge, others oppose it: the Home Office opposes discharge because of the risks posed by the patient

- the reports support discharge, but the Home Office considers that this is inappropriate because of the risks posed by the patient

- the reports support discharge, and the Home Office would consider discharge, but has not been asked to do so.

It is important that the tribunal members understand in each case the particular grounds on which the Home Office is opposing discharge.

\section{Home Office representation at tribunals}

Under the Mental Health Review Tribunal rules, any of the parties, including the Home Office, may be represented at the hearing. However, the Mental Health Unit only very rarely seeks representation at a tribunal hearing - typically, only about a dozen times a year. Representation is normally reserved for the small minority of cases where the risk to the public is assessed as potentially very serious and where it appears, from the reports received, that there is nevertheless a genuine prospect of discharge.

\section{The Home Office's relationship with tribunals}

The Home Office maintains close liaison with the Mental Health Review Tribunals service and has regular meetings to share, discuss and resolve issues of concern, as well as participating in the training of tribunal members on restricted cases. Guidance has been produced that sets out the various roles and responsibilities of those involved in Mental Health Review Tribunals for restricted patients (Home Office \& Mental Health Review Tribunal, 2004). 
Box 6 Potential reasons for recall by the Mental Health Unit

- A psychiatric or social supervisor recommends recall

- The patient possesses a weapon or becomes violent

- There is repetition of the behaviour that preceded the index offence (particularly if it involves drug or alcohol misuse)

- The patient is not adhering to medication regimens and is failing to keep appointments

- The patient has been admitted to hospital under civil powers (Sections 2 or 3 of the 1983 Act), as this would indicate that he could not be relied upon to remain in hospital voluntarily

\section{Recall to hospital}

Under Section 42(3) of the Mental Health Act 1983, the Home Secretary has the power to recall a conditionally discharged restricted patient to hospital. This power is exercised by the Mental Health Unit, and in 2004-5, 160 patients were recalled.

The principle by which the Unit operates the power of recall is that patients may be recalled if their mental disorder is causing them to behave in a way that is dangerous to themselves or others. Human rights legislation prevents the recall of a patient without evidence of mental disorder. However, it is not necessary for a patient to have suffered a relapse of mental illness. Box 6 sets out the circumstances in which the Mental Health Unit will recall or consider recalling a patient to hospital.

The Unit will not necessarily recall a patient who has reoffended. For example, it may be that the offence is unconnected with their mental disorder and their offending behaviour may be more effectively managed by the criminal justice system than by health services. The key question is whether or not a patient is judged to present a risk of harm. However, it is important to note that the Mental Health Unit may still recall a patient even though the clinical team take a different view.

Psychiatric or social supervisors who have concerns about a restricted patient in the community should contact the Mental Health Unit immediately to discuss the case. In urgent cases, a patient can be recalled immediately. If a decision is made to recall, the Mental Health Unit will issue a warrant as authority.

All restricted patients recalled to hospital are automatically referred to a Mental Health Review
Tribunal so that their detention may be reviewed. However, the Mental Health Unit is prepared to consider the discharge of any recalled patient, even before the tribunal has met, if he or she presents as settled and is no longer a risk to self or others.

\section{Transfer of prisoners to hospital}

Sentenced prisoners can be transferred from prison to psychiatric hospital under all four categories of mental disorder (mental illness, severe mental impairment, mental impairment and psychopathic disorder), under the provisions of Section 47 of the Mental Health Act 1983. Under Section 49, a restriction order may be imposed for the length of the prison sentence. However, remand, unsentenced and civil prisoners as well as immigration detainees can be transferred only for urgent treatment under Section 48 of the Mental Health Act if they are classified as suffering from the legal categories of mental illness or severe mental impairment. Although discretionary, a Section 49 restriction order is normally imposed in these cases. On receipt of the appropriate recommendations, the Mental Health Unit is responsible for issuing a warrant authorising the transfer on behalf of the Home Secretary. In an emergency, a prison transfer can be authorised out of hours. The prisoner will normally be returned to prison if and when reports are received indicating that no further treatment is required, or that no effective treatment can be given.

The Home Secretary is not obliged to act on a recommendation made under Sections 47 or 48 of the Mental Health Act. He needs to consider various factors (see Box 7) and whether it is right and expedient in the public interest to transfer a prisoner to hospital.

\section{Box 7 Factors considered by the Mental Health Unit in prison transfers}

- Whether the prisoner presents such a risk that he or she should remain in prison for the protection of the public

- Whether the prisoner is so notorious that transfer could undermine public confidence

- Any expressed intentions of the court in sentencing the person to imprisonment

- The possible outcome of a pending appeal against the prisoner's sentence

- Whether the medical treatment required can be adequately provided in a prison

- The length of time the prisoner still has to serve 
If transfer is considered appropriate, the Mental Health Unit's prime concern is to guard the public against any danger that might ensue should the individual escape from, or be improperly allowed out of, hospital. Among the issues considered by the Unit are the type and nature of the index offence, victim-related issues, previous convictions, any previous absconding, the prisoner's security category and his or her behaviour in prison.

\section{Working in partnership}

The Home Secretary's agreement is needed for a restricted patient's progress through and eventual discharge from the hospital. The Mental Health Unit's ability to fulfil its responsibilities depends enormously on the quality of information it receives from clinicians. Developing an effective and clear working relationship between the two is therefore essential.

The Mental Health Unit wants to strengthen its working relationships with its key partners. It is keen to engage directly, where possible and appropriate, with those responsible for patients' care.

\section{Case conferences}

One of the major developments over recent years has been the willingness of the Mental Health Unit to attend care programme approach and Section 117 meetings at which difficult issues are being discussed and where its presence will add value to the discussions. The increasing importance of multiagency public protection arrangements (MAPPA) in the management of conditionally discharged patients means more opportunities for joint working. The Home Office also encourages direct discussion of any complicated issues with Mental Health Unit caseworkers.

The Unit's involvement in these discussions helps all parties to develop a better understanding of ways in which a patient is best managed. Sometimes the Unit can give its views first hand on issues that might otherwise risk becoming complicated through the process of remote communication.

However, the Mental Health Unit's keenness to improve the partnership needs to be balanced against the size of case-loads (typically each grade 7 casework manager is personally responsible for about 750-800 patients) and the reality of its geographic location in London.

\section{Unit/region liaison}

Casework managers have responsibility for liaison with named areas of the country. Details of these responsibilities may be found on the Home Office website (http:// www. homeoffice.gov.uk). Hospitals, prisons and RMOs are encouraged to contact their link casework manager if there are any issues they wish to discuss.

\section{Visits to the Home Office}

The Mental Health Unit runs a programme of visits to the Home Office where, typically, a talk on the role of the Unit is followed by an opportunity to sit with caseworkers and see at first hand its working practices. In the past, these visits have been attended by a wide range of different groups, including clinical, nursing and administrative staff, who have reported them to be of value.

\section{New developments \\ Mental Health Bill}

The Home Office is working with the Department of Health to modernise mental health legislation to provide new safeguards for patients and to enable those who need treatment under compulsion to receive it in the most appropriate setting.

The Mental Health Act 1983 generally works well for diverting mentally disordered offenders from prison. The Mental Health Bill will amend the 1983 Act to introduce a single definition of mental disorder. This will give clinicians greater freedom to treat people on the basis of their need. The Bill will also introduce a new power enabling clinicians to discharge detained patients into the community to continue their treatment subject to conditions and a power of recall to hospital. This will give clinicians discretion to address the 'revolvingdoor' problem, where patients whose condition is stabilised in hospital relapse after discharge and have to be readmitted, for lack of powers to require their continuing 'compliance'.

\section{Domestic Violence, Crime and Victims Act 2004}

This Act makes a number of amendments to the legislation governing unfitness to plead and insanity.

Where a person was arraigned on or after 31 March 2005, when the new provisions came into force, it is the judge, rather than the jury, who determines the issue of whether a defendant is fit to plead. The Home Secretary no longer has a role in deciding whether or not the defendant is admitted to hospital: this is a matter for the court, which may make a hospital order with or without restrictions. 
The court also has a new range of disposals when it has made a finding of unfitness to plead and the defendant did carry out the act charged, or when it has found the defendant not guilty by reason of insanity under the 1964 Act. Where the court wishes to make an order for admission to hospital, it must apply the provisions of Section 37 of the Mental Health Act 1983, including the requirements for medical evidence.

The Act also contains provisions to give victims of offenders who receive restricted hospital orders, or who are transferred from prison to hospital, the same rights to information as are available to victims of offenders who receive a prison sentence. These provisions came into force on 1 July 2005.

\section{Conclusions}

\section{Does the partnership work?}

The main purpose of the restriction order is for the prevention of serious harm to the public. Reconviction rates are therefore important in measuring its effectiveness (Box 8).

\section{Box 8 Some comparisons}

Between 1986 and the end of 2001, 2049 restricted patients in England and Wales were conditionally discharged for the first time. Of these:

- fewer than 1 in $10(8 \%)$ were re-convicted of a standard-list offence within 2 years of discharge

- $1 \%$ were re-convicted for a grave offence (mainly offences of homicide, serious wounding, rape, buggery, robbery, aggravated burglary or arson)

Five-year re-conviction rates, which relate to those released between 1986 and 1998, were $16 \%$ for standard-list offences and 3\% for grave offences

Between 1997 and 2001, 10 (2\%) restricted patients were re-convicted for a sexual or violent offence within 2 years of discharge. This compares with an expected re-conviction rate of discharged prisoners of $11 \%$. The actual reconviction rate is therefore 9 percentage points lower than would be expected of discharged prisoners and those sentenced to community penalties who match the restricted patients on criminal history and demographic factors

(Ly \& Howard, 2004)

\section{Key messages}

- The role of the Home Office in relation to restricted patients primarily focuses on public protection. Its purpose is therefore different from that of the clinical team, but none the less it is crucial that good working relationships are established between the two. The Mental Health Unit places a great deal of importance on this.

- The Home Secretary is keen to encourage psychiatrists to submit requests for the discharge of restricted patients direct to the Home Office, rather than waiting for a Mental Health Review Tribunal to be convened.

- The monitoring of conditionally discharged patients in the community is a priority for the Mental Health Unit. It is essential that reports from supervisors are received on time and that the Unit is kept closely informed of patients' progress in the community.

- Should it prove necessary to recall a restricted patient to hospital, this need not necessarily entail a long period of further detention. The Mental Health Unit is prepared to consider the discharge of any recalled patient as soon as that individual presents as settled and it is assured that he or she is no longer a risk to self or others.

- The partnership between the Home Office and clinical teams is a successful one in preventing further offending.

\section{Declaration of interest}

S.D. is a casework manager in the Home Office Mental Health Unit in London.

\section{References}

Brennan, P., Mednick, S. \& Hodgins, S. (2000) Major mental disorders and criminal violence in a Danish birth cohort. Archives of General Psychiatry, 57, 494-500.

Department of Health (1998) Modernising Mental Health Services: Safe, Sound and Supportive. London: TSO (The Stationery Office).

Department of Health (1999) Report of the Expert Committee: Review of the Mental Health Act 1983. London: TSO (The Stationery Office).

Department of Health (2004) Draft Mental Health Bill (Cmnd 63051). London: Department of Health.

Department of Health and Social Services (1974) Revised Report of the Working Party on Security in NHS Psychiatric Hospitals (Glancy Report). London: TSO (The Stationery Office).

Home Office (2005) Domestic Violence, Crime and Victims Act 2004: Provisions for Unfitness to Plead and Insanity. Home Office Circular 24/2005. London: Home Office.

Home Office (2006) Notes for the Guidance of Supervising Psychiatrists: Mental Health Act 1983 Supervision and Aftercare of Conditionally Discharged Restricted Patients. London: Home Office. http:/ / www.homeoffice.gov.uk/documents/patientsupervise-psych-guidance

Home Office \& Department of Health and Social Services (1975) Report of the Committee on Mentally Abnormal Offenders (Butler Report) (Cmnd 6244). London: TSO (The Stationery Office). 
Home Office \& Mental Health Review Tribunal (2004) Joint Guidance Issued by Home Office and MHRT on Procedures to be Followed in Restricted Cases. http://www.mhrt.org.uk/ resources/other resources/mhrt guidance.htm

Ly, L. \& Howard, W. (2004) Statistics of Mentally Disordered Offenders 2003: England and Wales (Statistical Bulletin 16/04). London: Home Office.

\section{MCQs}

1 The Home Secretary is responsible for managing:

a mentally disordered offenders who are subject to restriction orders

b informal psychiatric patients

c mentally disordered offenders who are subject to restriction directions

d patients detained under Section 3 of the Mental Health Act 1983

e mentally disordered offenders who are subject to hospital directions under the Mental Health Act 1983.

\section{The Mental Health Unit:}

a has 67 staff, divided into nine caseworking teams

$\mathrm{b}$ has no role in the proposed draft Mental Health Bill

c operates only during the day

d employs one caseworker in charge of all the cases

e operates with reciprocal cover arrangements between caseworkers.

\section{The Mental Health Unit expects a risk assessment to} include:

a complete and objective analysis of risk

$\mathrm{b}$ whether a patient has made realistic progress

c likelihood of the patient doing harm

d circumstances leading to the risk of harm

e proposals to avoid the risk of harm.
4 The Mental Health Unit has a role to play in:

a granting community leave to restricted patients

$\mathrm{b}$ prescribing medication to restricted patients

c discharging restricted patients from hospital

d recalling restricted patients to hospital

e review of restricted patients by mental health tribunals.

5 As regards the Home Office:

a its main role is the protection of the public

b historically, partnership between the Home Office and clinical teams has been successful

c recall to hospital of a restricted patient always entails a long period of further detention

$\mathrm{d}$ it is not always necessary to update the Mental Health Unit about a restricted patient's progress in the community

e the Home Office wants psychiatrists to submit to it proposals for the discharge of restricted patients.

\begin{tabular}{|llllll|}
\hline MCQ answers & & & & \\
1 & & 2 & 3 & 4 & 5 \\
a T & a T & a T & a T & a T \\
b F & b F & b T & b F & b T \\
c T & c F & c T & c T & c F \\
d F & d F & d T & d T & d F \\
e T & e T & e T & e T & e T \\
\end{tabular}

